\title{
Inhibitors Incorporated Into Water-Based Epoxy Coatings on Metals for Corrosion Protection: A Review
}

\author{
Jilna Jomy ${ }^{1} \cdot$ Deepa Prabhu $^{2}$ (D) P. R. Prabhu ${ }^{3}$
}

Received: 30 August 2021 / Revised: 12 January 2022 / Accepted: 7 February 2022 / Published online: 21 February 2022

(c) The Author(s) 2022

\begin{abstract}
Corrosion and its protection are one of the major challenges that are faced by the industries. To overcome this, new coatings with characteristic properties which are environmentally friendly are introduced. A cost-effective and most reliable way of corrosion protection is via barrier coatings, in which water-based epoxy coatings showed significant corrosion resistance. Although the epoxy coating creates a barrier between the metal and the corroding ions, there is a chance of leakage due to mechanical rupture and the formation of micropores during the curing time of the epoxy. This leads to the incorporation of inhibitors into the epoxy coatings which in turn increase the corrosion resistance. This review discusses the different types of inhibitors that are incorporated into the epoxy coating to prevent corrosion. The use of Nano/micro containers for the encapsulation of the inhibitors leads to the discovery of self-healing smart coatings. Such water-based epoxy smart coatings are also discussed.
\end{abstract}

Keywords Smart coatings $\cdot$ Polymer $\cdot$ Organic-inorganic particles $\cdot$ Environment friendly

\section{Introduction}

\subsection{Metals and Corrosion}

Metals have a wide range of applications in industries like refineries, electronic industries automobiles, etc. The metals are subjected to different pretreatment processes such as acid cleaning, acid descaling, and oil well acidizing which leads to corrosion [1]. Corrosion is the deterioration of metal when subjected to different corrosive environments. The disruption of the physical protective barrier of the metal leads to several chemical reactions which in turn cause a change in

Deepa Prabhu

deepa.prabhu@manipal.edu

1 Department of Chemistry, Manipal Institute of Technology, Manipal Academy of Higher Education, Manipal, Karnataka 576104, India

2 Department of Chemistry, International Center for Applied Sciences, Manipal Academy of Higher Education, Manipal, Karnataka 576104, India

3 Department of Mechatronics, Manipal Institute of Technology, Manipal Academy of Higher Education, Manipal, Karnataka 576104, India the physical properties of the metal that leads to corrosion. Different types of corrosion occur in metals, which are uniform corrosion, crevice corrosion, intergranular corrosion, galvanic corrosion, stress corrosion, etc. [2]. The estimated cost of corrosion corresponds to $4.2 \%$ of the GDP of the US [3]. Since this process causes large economic losses, it is very important to prevent corrosion.

\subsection{Mitigation of Corrosion}

Scientists have employed different methods for corrosion protection such as cathodic protection, anodic protection, barrier protection using coatings, and use of corrosion inhibitors. Cathodic protection is the method of corrosion protection by the application of DC current on the metal thereby making it cathodic. There are two types of cathodic protection: galvanic protection and impressed current cathodic protection [3]. Although this type of protection gives optimum efficiency and safety, the cost-effectiveness and maintenance make it an unreliable method for corrosion protection.

Another potential method of corrosion prevention of metal is to make the metal anodic by the application of an anodic current. It involves the formation of a passive layer 
like oxides on the surface of the metal by increasing the metal potential. This oxide layer prevents the corrosive ions to penetrate the metal surface [4]. The major advantage is that it requires less current and can be applied to highly corrosive environments. Since the current applied for the anodic protection is equal to the corrosion rate of the metal, it gives a direct method for monitoring the corrosion rate [5]. The major disadvantage of anodic protection is that its lifespan is unknown, monitoring and designing are difficult.

When metals are subjected to aggressive environments to prevent corrosion, the use of inhibitors is considered as one of the acceptable practices. These inhibitors in small concentrations cause a significant decrease in the corrosion rate [6]. These inhibitors can be generally categorized into two (1) inhibitors that boost the oxide film which has a protective nature due to its oxidizing effect (2) inhibitors that get adsorbed on the metal surface forming a barrier layer for the aggressive ions [7]. Another most reliable and cost-effective methods for the mitigation of corrosion is barrier coatings. Barrier coatings are also modified using different inhibitors to exhibit self-healing mechanism. Such coatings are termed as smart coatings.

\subsection{Barrier Coatings}

Barrier coating provides a layer that prevents the passivation of corrosive ions to the metal surface [8]. Depending on the material, there are different types of coatings such as chromate conversion coatings, organic coatings, powder coatings, paints, etc. Earlier, chromate coatings were extensively used, but the government regulations regarding the environmental factors lead to the use of an alternative method of corrosion protection. Thus, came the importance of organic coatings. The organic coatings provide corrosion protection in two ways: (1) it acts as a physical barrier for the metal substrate (2) serves as a container for other compounds such as corrosion inhibitors. The organic coatings are classified based on the composition of resin in them. The common resins that are seen in the market are epoxy, acrylic, vinyl, alkyd, silicons, and urethane [9]. The properties of the coatings such as color, mechanical property, toughness, flexibility, opacity are controlled by the composition of these resins [10]. Epoxy coating shows characteristic properties such as high strength, low shrinkage, Excellent adhesion, Low toxicity, Low cost and excellent resistance to different chemicals and solvents [11]. But the disadvantage of using epoxy coating is that, during curing process of epoxy, large amount of toxic organic solvents are involved. In response to changing environmental regulations, there is a high demand for products with low solvent concentrations or environment-friendly solvents. Thus, water-based epoxy coatings are introduced.

\section{Water-Based Epoxy Coatings (WEP Coatings)}

An epoxy coating consists of a curing agent as polyamide, which has a high molecular weight and is crosslinked with epoxy. To satisfy the viscosity element during the application, the demand for a high solvent level has to be satisfied. There is an increase in the viscosity observed when the solvent is evaporated and high viscosity leads to fast drying. Solvent-free or when water is used as the solvent, synthesis of resin is performed to achieve crosslinking with high viscosity [12]. The WEP coating technology consists of two types based on the physical property of the epoxy resin which is illustrated in Fig. 1.

In the first type, when the curing agent and the epoxy (either liquid or semiliquid) are mixed, emulsion particles

TYPE 1

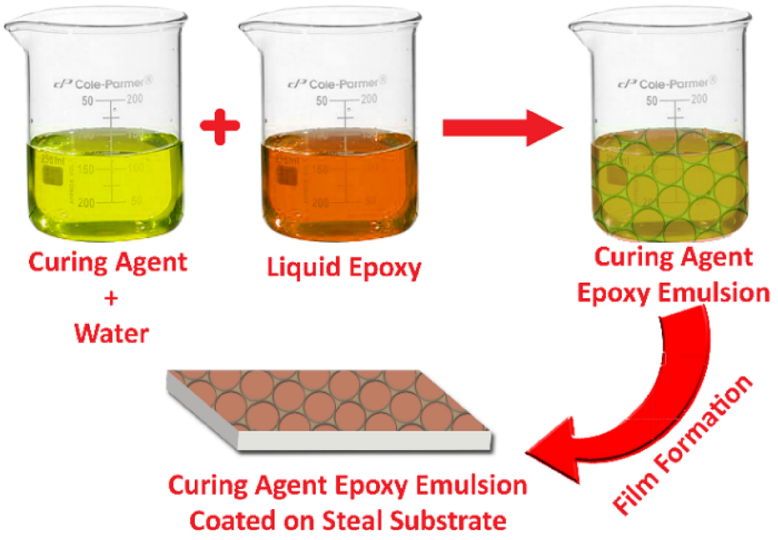

TYPE 2

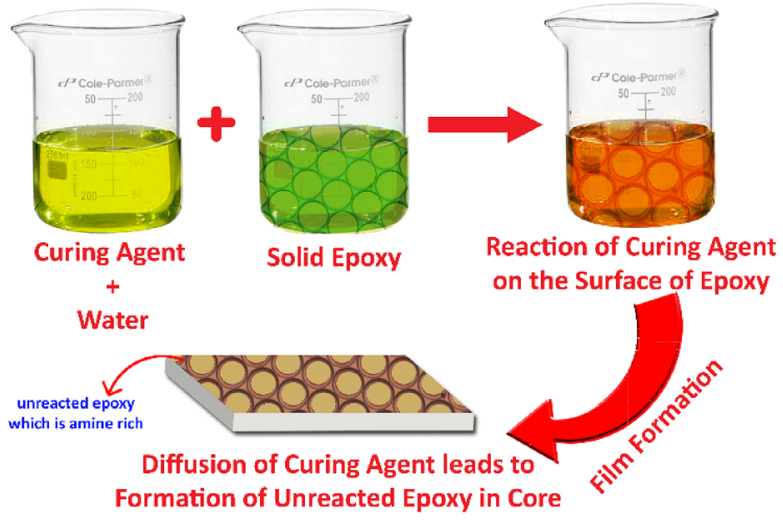

Fig. 1 Types of WEP coating based on the physical property of the epoxy resin 
are formed. This typically leads to high strength, gloss, adhesion for the coating. The second type, the curing agent and epoxy does not emulsify the resin as a result the curing agent attacks the surface, which results in unreacted epoxy (amide rich) at the core. As the coating gets coalesce into the metal, the unpaired electrons on the amide group can be donated to vacant orbital of the metal which leads to good adhesion, corrosion protection, and longer life [12]. Although epoxy coating acts as a barrier between the metal and the environment, it is not a perfect barrier as water, ions can penetrate the metal surface during certain conditions such as mechanical rupture and chemical rupture. Thus, there is a need for the incorporation of other corrosion inhibiting particles into the WEP coatings [13]. Through these years scientists have modified the WEP by incorporating different particles such as polymers, nanoparticles, and graphene that are illustrated in Fig. 2.

\subsection{Graphene Incorporated WEP Coatings}

Graphene has a wide range of applications due to its unique characteristics such as chemical inertness, high electrical property, and good impermeability for corrosive medium [14]. This makes graphene a successful candidate for corrosion protection. It has a high surface area and strong van der Waals interaction which makes it unite with the metal matrix [15-17]. Different methods have been employed to produce graphene-based coatings such as physical vapor deposition, chemical vapor deposition, and electrodeposition, etc. [18-20]. A different liquid-phase exfoliation method is used by Cui et al. for the successful incorporation of graphene oxide modified polydopamine into the WEP coating and evaluated the corrosion resistance [21]. Phenosafranin was incorporated into graphene (PSF@G) which leads to high dispersion of graphene in water due to $\pi-\pi$ interaction of the large aromatic system of PSF and graphene surface. The

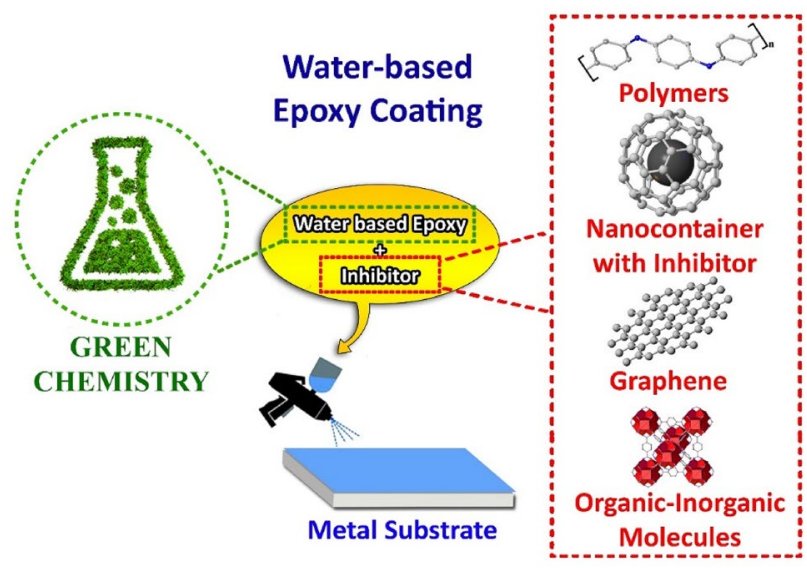

Fig. 2 Modiffication of WEP coating incorporating various particles coatings formed gave EIS results for the long term and the salt test confirmed that the durability and impedance are significantly improved which implies that the incorporation of graphene has slowed down the penetration of corrosive ions. He also studied the effect of the incorporation of graphene oxide-polydopamine into the epoxy coating. The polydopamine showed great compatibility and dispersion in the WEP coating. This coating with mechanical damage prevented corrosion in a better way than pure epoxy coating [19]. To study the effect of graphene with the different structures on the WEP coatings, two types of graphene powder Ga and $\mathrm{Gb}$, graphene oxide and graphene slurry was used and from the EIS study, it was seen that Ga produces optimum corrosion protection characteristics for an immersion time of 32 days [22]. The coating exhibited higher integrity and proved that lower defects lead to higher barrier protection $[23,24]$. There is evidence for the development of a small hydrophobic character and improved corrosion electrochemical behavior in aluminum when graphene is incorporated [25]. It's also proved that the presence of graphene does not alter the structural properties of the resin [26].

The effect of incorporation of lignin into graphene epoxy coating was studied by Xingnan Zhou et al. The result suggests that the corrosion resistance of lysine-GO-epoxy coatings is two-fold higher than GO epoxy coating. The remarkable improvement in the dispersion of lignin-GOepoxy coating is demonstrated using SEM in Fig. 3 [28]. Zhou et al. have studied the effect of corrosion resistance of WEP coating by the addition of graphene oxide modified with phytic acid in mild steel substrate. Enhanced dispersion ability, anticorrosion activity, and less delamination were observed [29]. In another experiment performed by Wang et al. modified GO with zeolitic molecular sieves (ZSM5) was introduced into WEP coating. It was found that the adhesion of the composite was significantly increased $42 \%$ when compared to the pure epoxy coating [30]. Functionalization of GO with polyetheramine and the corrosion along with weather resistance was explained by $\mathrm{Li}$ et al. The residual hardness of the composite at $0.5 \mathrm{wt} \%$ of polyethramine/ GO was three times higher than the pure epoxy. Enhanced weathering resistance was also observed [31]. Polyacrylated phosphorus monomer was used in the functionalization of graphene oxide. The vinyl group reacts with the thiol group to form the compound, which later was used for the modification of GO. High corrosion inhibition efficiency at a concentration of $0.5 \mathrm{wt} \%$ was achieved [32]. Lysine (LY) was modified using GO nanosheets and was filled into the epoxy coating. The LY-GO increased the cross-linking density of the WEP coatings due to the reaction between the amine group of the LY and the epoxy resin [27].

Zhong et al. modified graphene using tannic acid (TA) and self-assembled it with polyaniline enwrapped on Vanadium oxide $\left(\mathrm{V}_{2} \mathrm{O}_{5}\right)$. The self-healing property observed in 
Fig. 3 The compatibility of lysine-GO with the epoxy is demonstrated through SEM images of $\mathbf{a}$ and $\mathbf{b}$ The pure epoxy shows a relatively smoother surface. $\mathbf{c}$ and $\mathbf{d}$ This shows the incorporation of $0.2 \mathrm{wt} \%$ Epoxy GO leads to some amount of agglomeration e and $\mathbf{f}$ shows $0.3 \mathrm{wt} \%$ lysineepoxy-GO coatings which are well distributed. Reprinted with permission from Ref. [27]. Copyright 2019: Elsevier
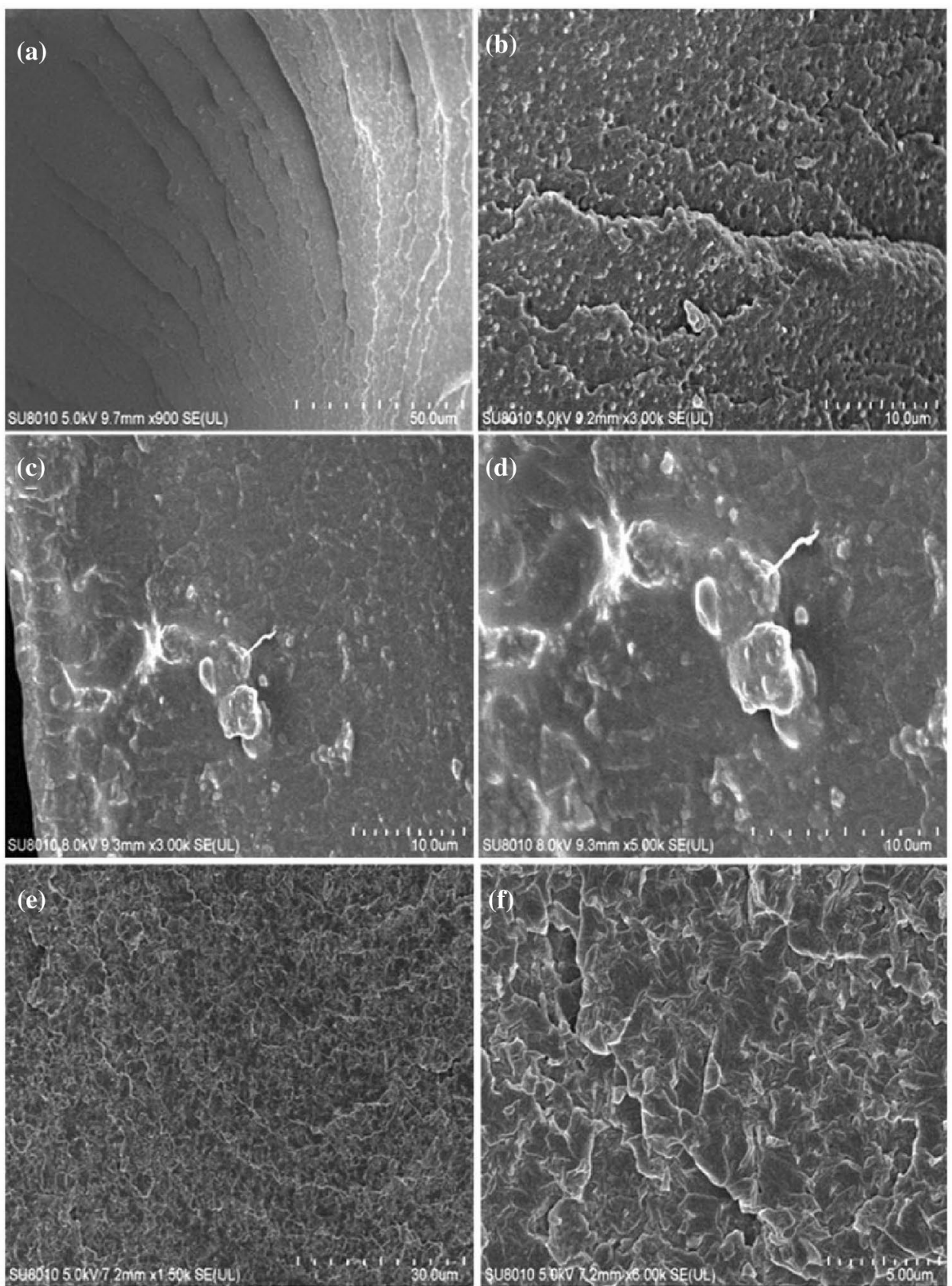

the coating is due to the complex formation of TA-Fe-TA and also due to the oxide layer formed at the coating interface [33]. Amania et al. have synthesized graphene oxide decorated with nanoparticles of $\mathrm{Fe}_{2} \mathrm{O}_{3}$ and incorporated it into the WEP coatings. The synthesis was achieved using emulsion polymerization and the good dispersion without agglomeration of $\mathrm{GO} / \mathrm{Fe}_{2} \mathrm{O}_{3}$ was observed [34]. Enhancement in corrosion property was achieved by the addition of graphene along with halloysite nanotubes into WEP coatings was studied by Ye et al. Densification of the epoxy occurs when the nanofillers are introduced, which prevents the micropore formation during the curing process of the epoxy that prevents the permeation of the corrosive ions [35]. Ye synthesised carbon dots was modified with graphene and used as a filler for WEP coatings. For these coating, a two-fold increase in the modulus of impedance was achieved after an immersion time of 50 days and a decrease in the water absorptivity when compared to pure epoxy [36]. The studies regarding the modification of graphene into the WEP coatings are illustrated in Table 1. 


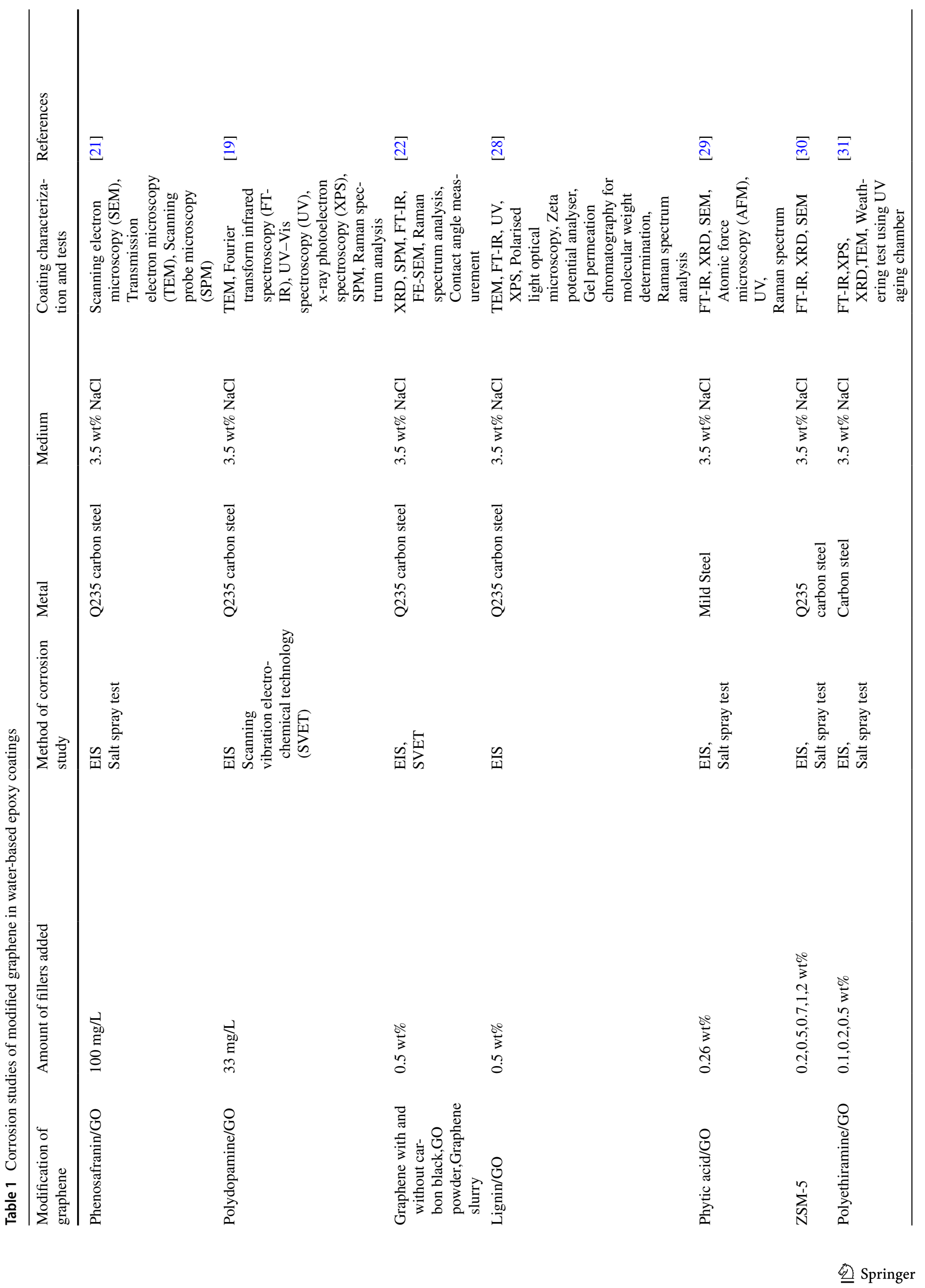




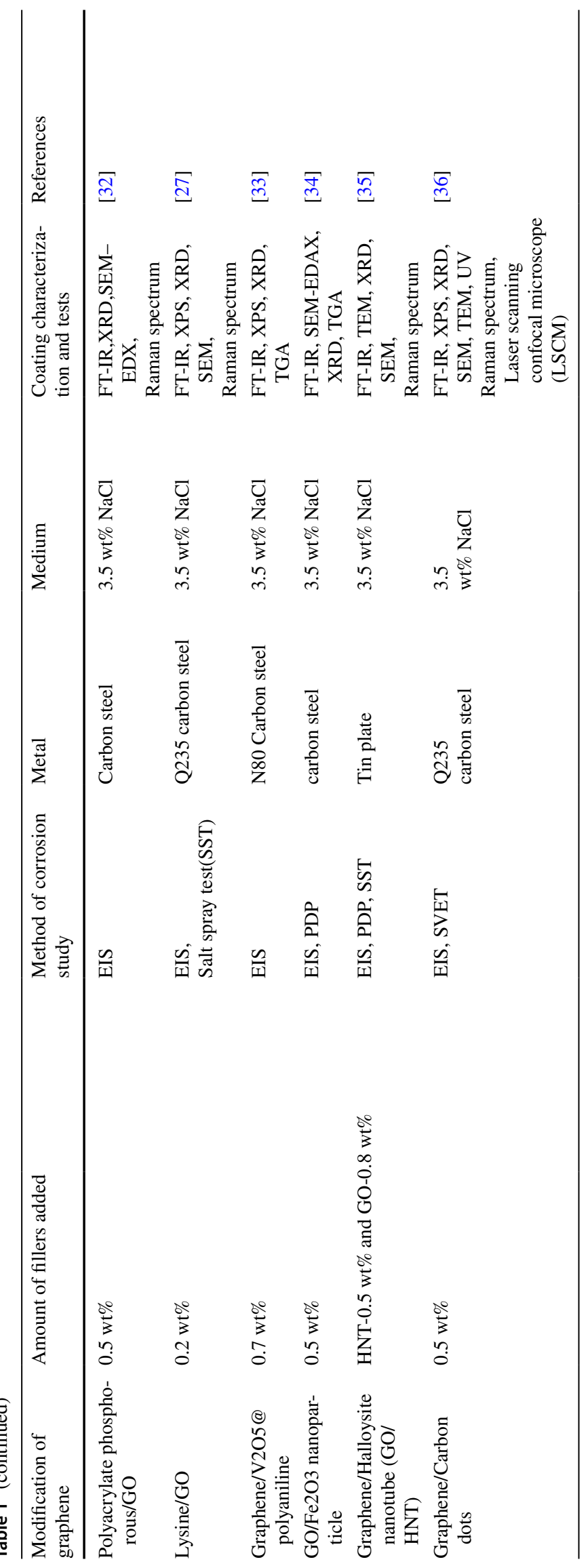




\subsection{Polymer Incorporated Water-Based Epoxy Coatings}

The anti-corrosion property of conductive polymers such as polyaniline, polyethylamine, polyethylene, polythiophene, polypyrrole has received significant interest among researchers [37-40]. Due to high electrical conductivity, simplified synthesis procedure, and low cost, the conductive polymer-polyaniline is widely studied [41-44]. The reason behind the high corrosion resistance is the redox catalytic nature of the polyaniline. Different inorganic or inorganic particles can improve the toughness, strength and stiffness of the polymer. The improvement in mechanical properties of a polymer depends on the particle size, particle loading and the interface interaction between the particle and matrix.

Bagherzadeh et al. have successfully synthesized polyaniline epoxy composite coatings and determined their corrosion property by electrochemical impedance which showed a significant decrease in the corrosion rate. A uniform oxide layer was produced which results in the lesser dissolution of metal when the polyaniline was used in the nanoscale. The micrometer-scale polyaniline showed greater water adsorption which leads to higher corrosion resistance [45]. SEM and TEM images of these nano and micro-scale polyaniline epoxy coating are illustrated in Fig. 4. His group also synthesized nanoemeraldine salt polyaniline which showed more corrosion resistance than polyaniline at a concentration as small as $0.02 \mathrm{wt} \%$. But adherence to this coating was found to be the same as that of the polyaniline [46]. Polyaniline in the form of nanotubes, nanoparticles, and nanofibers has a wide range of applications in manufacturing electrical sensors, supercapacitors, and battery electrodes [47-49]. The polyaniline was synthesized in the form of nanofiber by Qiu et al., and the corrosion resistance property was determined. The
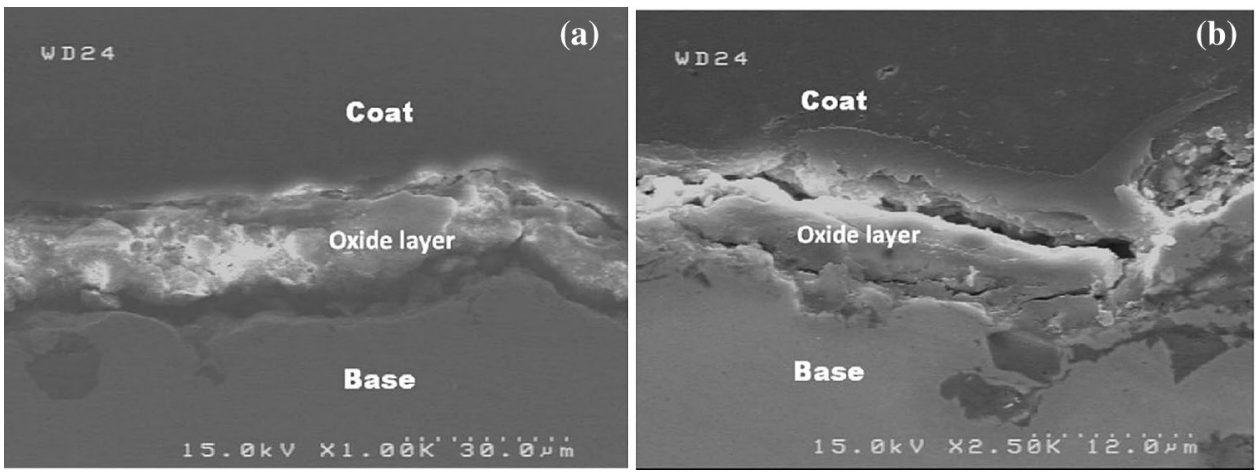

Fig. 4 SEM images of 1 a nanoparticle polyaniline 1 b microparticle polyaniline in the metal coatings. Better uniformity of the oxide layer is seen in nanoparticle polyaniline which proves that there is more uniform distribution than microparticle polyaniline. The parti2007: Elsevier resulting nanofiber exhibits excellent aqueous solubility, good conductivity, and reversible activity which increase the corrosion property of the coating [50].

It was found that the presence of a dense film of phosphating group, implies that it can act as a corrosion inhibitor [51, 52]. By using this characteristic of phosphate groups Chetan et al. have developed phosphorylated polyvinyl alcohol doped with polyaniline nanoparticles as a potential anticorrosion coating [53]. Furthermore, polyaniline doped with ethylene units containing phosphates was studied for their anti-corrosion property [54]. Phosphoric acid doped polyaniline nanoparticles were synthesized and incorporated into water-borne epoxy coatings. The increased inhibitive action of the coating was attributed to the catalytic property of polyalanine and doping anions inhibitory effect [55].

A mussel-inspired polyaspartamide derivative (DOPA) was incorporated into WEP coating by Yang et al. The corrosion protection of DOPA is due to the formation of a polymer-Fe complex which forms a thin film. Significant improvement in the barrier properties was observed when it is subjected to aerated conditions due to the conversion of DOPA into DOPA-quinone by oxygen molecule which in turn reacts with the Fe ions released on the metal surface [56]. Fabrication of mesoporous $\mathrm{TiO}_{2}$ modified with polyethylenamine was executed by Wang et al. Reduction in the transport path of the corrosive medium on the metal surface was observed due to interaction between polyethylenamine and epoxy [57]. Different morphologies of polythiophene microspheres were synthesized and added into WEP coatings by Ai et al. Uniform dispersion of polythiophene in the epoxy coating was achieved due to the narrow distribution of the particle size and uniform size of the particles [58].

Mesoporous silica (MCM-41) with and without template was synthesized and the pores are filled with cetyl trimethylammonium bromide (CTAB) and Pluronic F-127 and were coated into polyaniline coated epoxy metal specimen.

cle is determined by TEM images 2 a nanoparticle polyaniline has a particle size of $50 \mathrm{~nm}$ and $2 \mathbf{b}$ microparticle polyaniline has a particle size of 1-3 $\mu \mathrm{m}$. Reprinted with permission from Ref. [45]. Copyright 
Polyalanine acts as a physical barrier for corrosion. Better curing rate and high electron density was obtained for coatings prepared through in-situ polymerization without template than with template [59]. Another modification of the polyaniline was performed using $\mathrm{TiO}_{2}$ nanoparticles and was dispersed into the WEP coatings. The highest impedance for the prepared coating was observed after the immersion of
14 days [60]. Polyaniline/ Montmorillonite clay composite was introduced to WEP coatings. The increase in the barrier property was due to the good dispersion of silicone nanolayers of montmorillonite in polyaniline matrix [61]. $\mathrm{V}_{2} \mathrm{O}_{5}$ was modified using polyaniline and tannic acid and used as a filler for the WEP coatings. After 80 days of immersion time, the impedance modulus was found to be in the order

Table 2 Corrosion protection of Polymer incorporated water-based epoxy coating

\begin{tabular}{|c|c|c|c|c|c|c|}
\hline $\begin{array}{l}\text { Polymer incorpo- } \\
\text { rated }\end{array}$ & $\begin{array}{l}\text { Amount of fillers } \\
\text { added }\end{array}$ & $\begin{array}{l}\text { Method of corrosion } \\
\text { study }\end{array}$ & Metal & Medium & $\begin{array}{l}\text { Coating characteri- } \\
\text { zation and tests }\end{array}$ & References \\
\hline $\begin{array}{l}\text { Nano/Micro poly- } \\
\text { aniline }\end{array}$ & $\begin{array}{l}\text { Nano PAni- } \\
0.01 \text { wt } \% \\
\text { Micro PAni- } 0.3 \text { wt } \%\end{array}$ & Salt spray test (SST) & Carbon steel & $3.5 \mathrm{wt} \% \mathrm{NaCl}$ & $\begin{array}{l}\text { Dynamic light } \\
\text { scattering (DLS), } \\
\text { TEM, (SEM) }\end{array}$ & [45] \\
\hline $\begin{array}{l}\text { Nanoemeraldine } \\
\text { salt-polyaniline }\end{array}$ & $0.02 \mathrm{wt} \%$ & SST & Q235 & $3.5 \mathrm{wt} \% \mathrm{NaCl}$ & $\begin{array}{l}\text { Dynamic light } \\
\text { scattering (DLS), } \\
\text { TEM, SEM }\end{array}$ & [46] \\
\hline $\begin{array}{l}\text { Sulphonated } \\
\text { polyaniline(PAni) } \\
\text { nanofibre }\end{array}$ & $0.5,1,2 \mathrm{wt} \%$ & EIS & Q235 & $3.5 \mathrm{wt} \% \mathrm{NaCl}$ & $\begin{array}{l}\text { F-TIR, x-ray diffrac- } \\
\text { tion (XRD), SEM, } \\
\text { TEM, UV, Raman } \\
\text { spectrum analysis, } \\
\text { x-ray photoelectron } \\
\text { spectroscopy } \\
\text { (XPS) }\end{array}$ & {$[50]$} \\
\hline $\begin{array}{l}\text { PAni/Partially } \\
\text { phosphorylated } \\
\text { (polyvinylalcohol) } \\
\text { nanoparticle }\end{array}$ & $1,2.5,4 \mathrm{wt} \%$ & $\begin{array}{l}\text { EIS, } \\
\text { SST }\end{array}$ & Mild steel & $3.0 \mathrm{wt} \% \mathrm{NaCl}$ & XPS, SEM & [53] \\
\hline $\begin{array}{l}\text { Polyaniline/Polyvi- } \\
\text { nylpyrrolidine }\end{array}$ & $1 \mathrm{wt} \%$ & EIS & Q235 carbon steel & $3.5 \mathrm{wt} \% \mathrm{NaCl}$ & $\begin{array}{l}\text { FT-IR, XPS, XRD, } \\
\text { SEM, } \\
\text { Raman spectrum, } \\
\text { UV, TEM }\end{array}$ & [55] \\
\hline Polyaspartamide & $5 \mathrm{wt} \%$ & EIS & Q235A carbon steel & $3.5 \mathrm{wt} \% \mathrm{NaCl}$ & $\begin{array}{l}\text { FT-IR, SEM, Dif- } \\
\text { ferential scanning } \\
\text { calorimetry( DSC) } \\
\text { Raman spectrum, }\end{array}$ & [56] \\
\hline $\begin{array}{l}\text { Polyethylenamine/ } \\
\text { mesoporous } \mathrm{TiO}_{2}\end{array}$ & $0.4 \mathrm{wt} \%$ & $\begin{array}{l}\text { EIS, } \\
\text { SST }\end{array}$ & Mild steel & $3.5 \mathrm{wt} \% \mathrm{NaCl}$ & $\begin{array}{l}\text { FT-IR, TGA, SEM, } \\
\mathrm{N}_{2} \text { Adsorption } \\
\text { desorption iso- } \\
\text { therm }\end{array}$ & [57] \\
\hline $\begin{array}{l}\text { Polythiophene } \\
\text { microspheres }\end{array}$ & $0.6 \mathrm{wt} \%$ & EIS & Q235 carbon steel & $3.5 \mathrm{wt} \% \mathrm{NaCl}$ & $\begin{array}{l}\text { Dynamic light } \\
\text { scattering (DLS), } \\
\text { FT-IR, FE-SEM, } \\
\text { FE-TEM, TGA }\end{array}$ & {$[58]$} \\
\hline $\begin{array}{l}\text { Polyanaline- } \\
\text { mesoporous } \\
\text { MCM-41 }\end{array}$ & $1.2 \mathrm{wt} \%$ & EIS, SST & Q235 carbon steel & $3.5 \mathrm{wt} \% \mathrm{NaCl}$ & $\begin{array}{l}\text { FT-IR, XRD, Ther- } \\
\text { mogravimetric } \\
\text { analysis (TGA), } \\
\text { SEM, } \mathrm{N}_{2} \text { Adsorp- } \\
\text { tion desorption } \\
\text { isotherm }\end{array}$ & [59] \\
\hline $\begin{array}{l}\text { Polyaniline-TiO2 } \\
\text { nanoparticle }\end{array}$ & $1 \mathrm{wt} \%$ & $\begin{array}{l}\text { EIS, Scanning } \\
\text { electrochemi- } \\
\text { cal microscopy } \\
\text { (SCEM) }\end{array}$ & Q235 carbon steel & $\begin{array}{l}0.5 \mathrm{M} \mathrm{NaCl} \text { solu- } \\
\text { tion }\end{array}$ & $\begin{array}{l}\text { FT-IR, XRD, } \\
\text { Contact angle } \\
\text { measurement and } \\
\text { SEM, }\end{array}$ & {$[60]$} \\
\hline $\begin{array}{l}\text { Polyaniline-Mont- } \\
\text { morillonite }\end{array}$ & - & EIS,PDP & Mild steel & $3.5 \mathrm{wt} \% \mathrm{NaCl}$ & FT-IR, XRD & {$[61]$} \\
\hline $\begin{array}{l}\text { V2O5@Polyaniline- } \\
\text { tannic acid }\end{array}$ & - & EIS, SST & P110 steel & $3.5 \mathrm{wt} \% \mathrm{NaCl}$ & $\begin{array}{l}\text { FT-IR, XRD, TGA, } \\
\text { SEM, TEM, XPS }\end{array}$ & {$[62]$} \\
\hline
\end{tabular}


$10^{8} \Omega / \mathrm{cm}^{2}$ [62]. The different polymers incorporated into water-borne epoxy coatings are illustrated in Table 2.

\subsection{Organic-Inorganic Hybrid Particles that Are Incorporated Into the Water-Based Coating}

In recent years, organic-inorganic hybrid molecules have been used in enhancing the anticorrosion activity of waterbased epoxy coating [63]. One such molecule is the organofunctional silanes, which have a formula $(\mathrm{ROH})_{3} \mathrm{SiY}$, where $\mathrm{ROH}$ is the alkoxide group and $\mathrm{Y}$ is the organofunctional groups such as active amine groups. It has been found that epoxy-silica mixture provides enhanced adhesion and characteristic corrosion inhibition activity [64-67]. Bagherzadeh et al. have used 3-glycidoxypropyl trimethoxy silane to produce water-based epoxy coatings, which confirmed decreased level of pores, defects, and good distribution of particles in the epoxy coating [63]. Another organic-inorganic hybrid molecule is the use of metal-organic frameworks (MOF) as a potential anticorrosion water-based epoxy coating. MOF has characteristic properties such as high porosity, surface area, and is used for a wide range of applications such as gas sensing, catalysis, and drug delivery [68]-[71]. Na Wang et al. have produced a MOF-5 incorporated water-borne epoxy coating with dopamine covering. It was shown that with the incorporation of $0.5 \mathrm{wt} \%$ of MOF-5, corrosion resistance of $3.18 \times 10^{8} \Omega / \mathrm{cm}^{2}$ was obtained [72].

\section{Smart Coating}

Corrosion protection of metal generally involves the creation of a barrier layer between the aggressive environment and the metals, when an inhibitor is added to the coating formulation. Due to aging, leaching of these inhibitors can take place which reduces the efficiency of these inhibitors [73]-[77]. To prevent these scientists have started using nano or micro containers to load these corrosion inhibitors, which are compatible with the metal matrix. These came to be known as smart coatings [78-85]. The mechanism of action of the smart coating is illustrated in Fig. 5. The inhibitor encapsulated protective system delivers the inhibitors in a controlled manner, on exposure to different stimuli like $\mathrm{pH}$ change that is occurring due to UV irradiation, aggressive ions, and different redox activity [86]-[93]. This ensures the long-term performance of the coatings. Due to the change in $\mathrm{pH}$, redox activity starts on the metal surface. This makes the $\mathrm{pH}$-sensitive containers a promising system for encapsulation of corrosion inhibitors.

Snihirova et al. introduced a smart corrosion protective system consisting of $\mathrm{CaCO}_{3}$ microbeads modified with several corrosion inhibitors like cerium ions, salicylaldoxime and 2,5-dimercapto-1,3,4-thiadiazolate (DMTD) impregnated into WEP coatings in AA204 coupons. $\mathrm{CaCO}_{3}$ microbeads showed good dispersion and these loaded with cerium nitrate showed the highest resistance

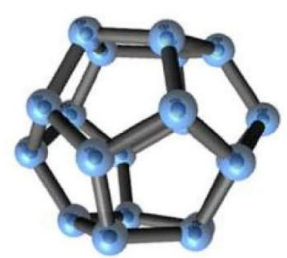

Nanocontainer

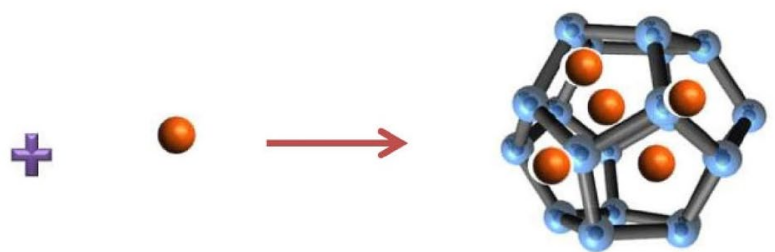

Inhibitor

\section{Inhibitor embedded inside the nanocontainer}

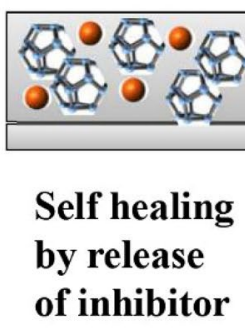

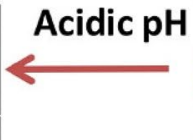

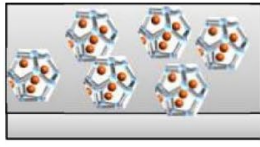

Metal substrate

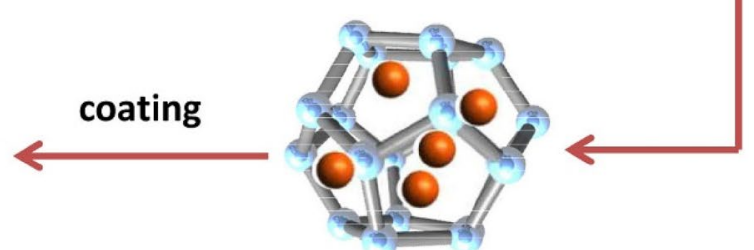

Nanocontainer is wrapped using a $\mathrm{pH}$ sensitive gate keeper

Fig. 5 Mechanism of action of a smart coating 
[94]. A new polyelectrolyte nanocapsule smart container was synthesized by Kope et al. by the mechanism of adsorption of polyelectrolyte on the oil phase emulsion droplet of the inhibitors 2-methylbenzothiazole (BT) and 2- mercaptobenzothiazole (MBT) [95]. Although the nanocapsules were found to have great compatibility with the WEP coatings, the need to optimize the capsule concentration is emphasized. The scheme of release of inhibitor on response to $\mathrm{pH}$ is given in Fig. 6.

Another polyelectrolyte nanocapsule modified $\mathrm{TiO}_{2}$ hollow spheres were used as an inhibitor containing container synthesized by a layer-by-layer mechanism. For this nanocontainer, maximum release behavior was obtained in an alkaline medium [97]. $\mathrm{TiO}_{2}$ nanocontainer was also used for the encapsulation of mercaptobenzimidazole and it was modified using a $\mathrm{SiO}_{2}$ covering. From the experiments, it was found that the maximum amount of release is at $\mathrm{pH} 2$ and $\mathrm{TiO}_{2}$ is found to exhibit high dispersity inside the epoxy resin [98].

An ecofriendly smart coating was prepared using porous carbon nanosheets (PCNS) synthesized by exfoliating biomass from fallen leaves and by loading phytic acid onto the holes and amino-propyltriethoxysilane (APTES) into the surface of the PCNS. The ATPES grafted to the surface is found out to be acting as a protective layer against corrosion and the phytic acid is found to be able to chelate the products of corrosion thus repairing the cracks [99]. A pH-sensitive polymer Eudragit particle was used as a reservoir to contain corrosion inhibitor 8-hydroxyquinoline as a filler for WEP coatings. During the impedance study, an evolution of a localized impedance was observed, this points out the effectiveness of the compound to prevent the local corrosion in the damaged regions [96]. The LEIS mapping of the coatings formed is give in Fig. 7.
$\mathrm{CeO}_{2}$ hollowspheres is used as a carrier for inhibitor benzatriazole and self-healing action of it on WEP coatings were studied. In alkaline conditions, the release of inhibitor was found to be minimum. The charge transfer resistance $\left(R_{\mathrm{ct}}\right)$ value for the inhibitor-loaded coating was found to be $3.5 \times 10^{5} \mathrm{Ohm} \mathrm{cm}{ }^{2}$ and epoxy coating to be $2.8 \times 10^{5} \mathrm{Ohm}$ $\mathrm{cm}^{2}$. The increase in the $R_{\mathrm{ct}}$ value shows that a thin adsorptive layer of the inhibitor is formed that prevents corrosion [100]. Liu et al. synthesized mesoporous chitosan nanospheres encapsulated with sodium phytate and were added into WEP coatings. The rate of loading of sodium phytate was found to be $25.79 \mathrm{wt} \%$ and the fastest release was observed at a pH of 9 [101]. The slow-release of nanofiller Lecithin-SiO2- Etidroic acid introduced into WEP coating was analyzed by Wang et al. The synthesized nanofiller showed one order greater magnitude of impedance with the maximum inhibition efficiency of $80.7 \%$ [102]. Different corrosion inhibitors incorporated into various nanocontainers/microcontainers are illustrated in Table 3.

\section{Summary and Future Prospectives}

The development of modified water-based epoxy coating finds application due to the increase in the demand for environmentally friendly coatings in industries. The electrochemical impedance measurements showed that the addition of corrosion inhibiting particles such as polymers, nanoparticles, and others showed an increase in the corrosion inhibition efficiency. The development of smart coatings made way to the introduction of a better coating with double inhibition with other characteristics like self-healing. The advantages and disadvantages of the various additives in the WEP coatings are illustrated in Table 4.
Fig. $6 \mathrm{pH}$ sensing response from the Eudragit particles loaded with 8- hydroxyquinoline. Reprinted with permission from Ref. [96]. Copyright 2014: Elsevier

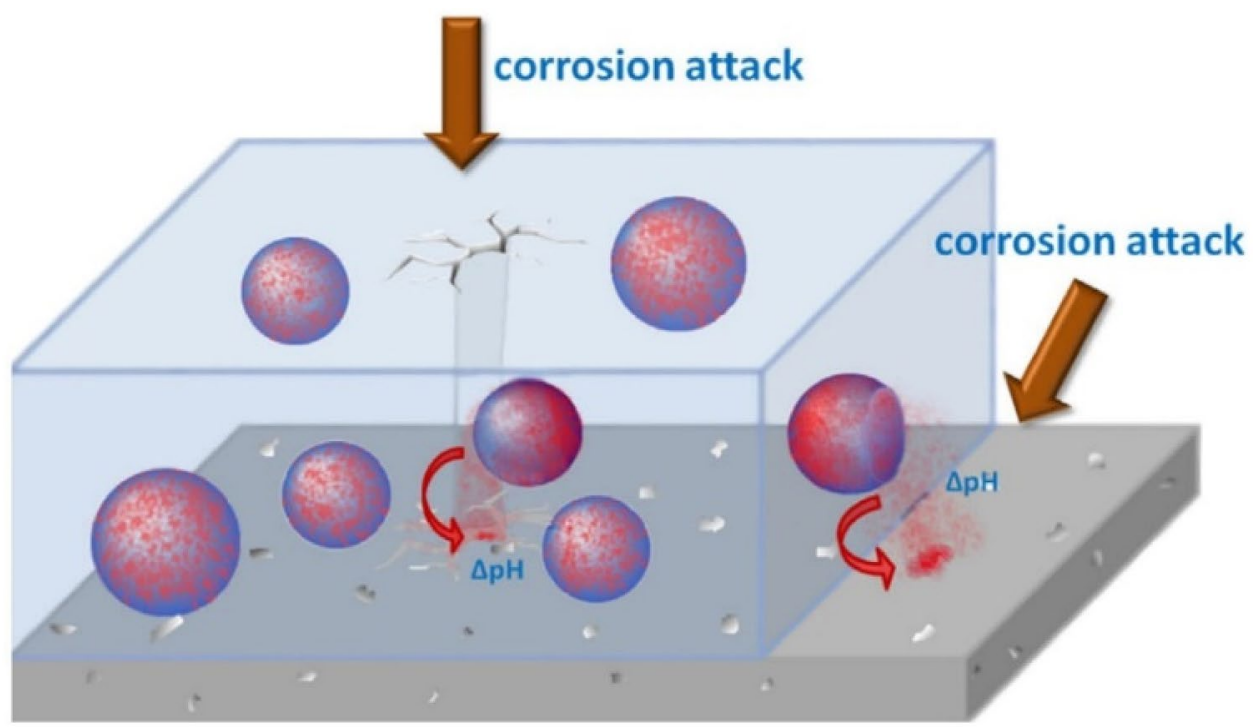



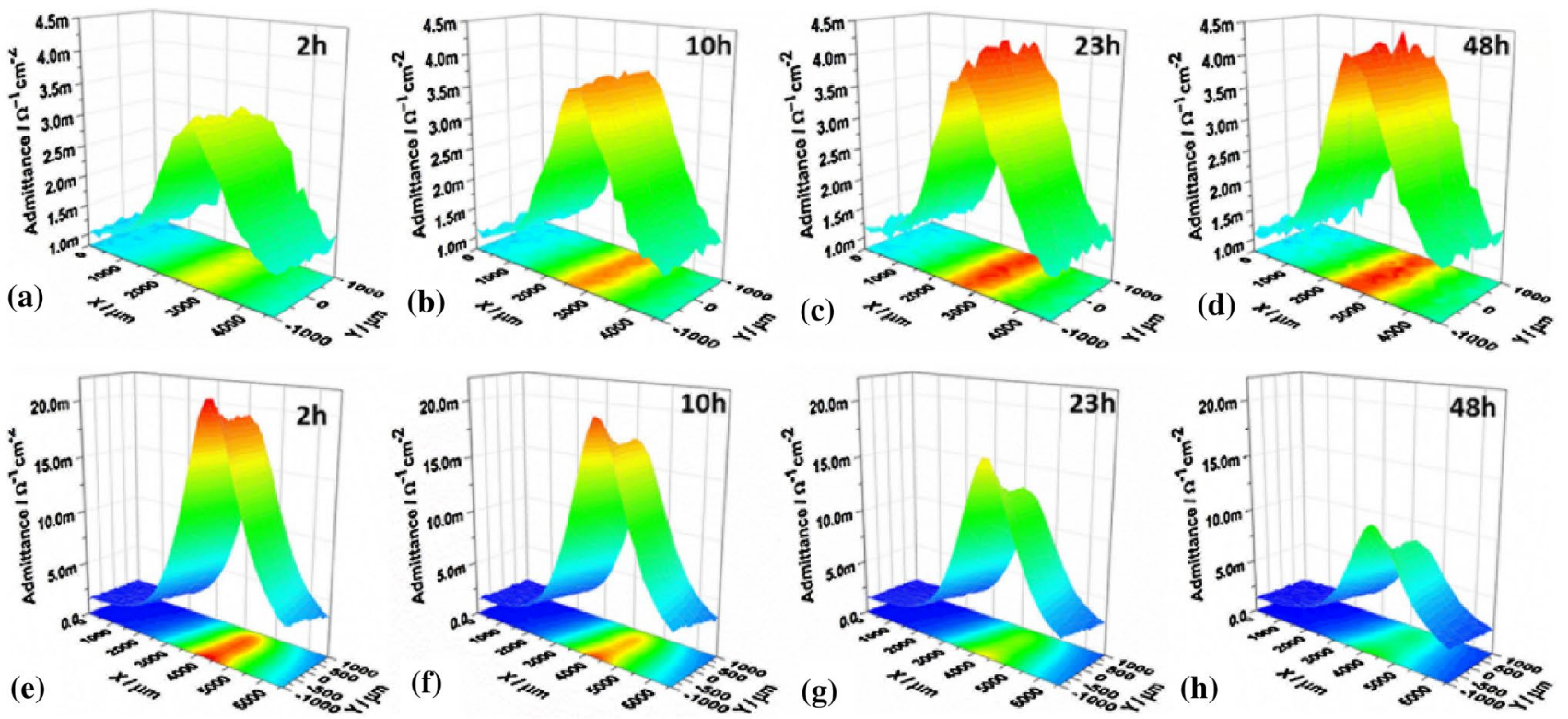

Fig. 7 LEIS mapping of $\mathbf{a}$ and $\mathbf{d}$ reference coatings and $\mathbf{e}$ and $\mathbf{h}$ coatings incorporated with Eudragit particles modified with 8 hydroxyquinoline. The increase in the admittance shows higher corrosion activity. The reference coating showed an increase in admittance

with immersion time but the particles incorporated coatings showed a decrease in admittance with immersion time which shows that the active area is getting healed by the inhibitor. Reprinted with permission from Ref. [96]. Copyright 2014: Elsevier

Table 3 Corrosion inhibition of different inhibitors incorporated in nano /micro containers

\begin{tabular}{|c|c|c|c|c|c|c|}
\hline Nano/Microcontainer & Corrosion inhibitor & $\begin{array}{l}\text { Amount of } \\
\text { containerwith } \\
\text { inhibitor }\end{array}$ & $\begin{array}{l}\text { Method of corrosion } \\
\text { studies }\end{array}$ & Metal & Medium & References \\
\hline $\mathrm{CaCO}_{3}$ microbead & $\begin{array}{l}\text { cerium nitrate, salicyla- } \\
\text { ldoxime } \\
\text { and 2,5-dimercapto- } \\
\text { 1,3,4thiadiazolate }\end{array}$ & $5 \mathrm{wt} \%$ & EIS & AA204 & $3.5 \mathrm{wt} \% \mathrm{NaCl}$ & [94] \\
\hline $\begin{array}{l}\text { Polyelectrolyte nano- } \\
\text { capsule }\end{array}$ & $\begin{array}{l}\text { 2-methylbenzothiazole } \\
\text { 2mercaptobenzothia- } \\
\text { zole }\end{array}$ & - & EIS,SST & AA2024T3 & $\mathrm{NaCl}\left(0.05 \mathrm{~mol} \mathrm{dm}^{-3}\right)$ & [95] \\
\hline $\mathrm{TiO} 2$ nanocontainer & benzotriazole & $1.5 \mathrm{wt} \%$ & $\begin{array}{l}\text { EIS, scanning Kelvin } \\
\text { probe (SKP) }\end{array}$ & Q235 & $0.5 \mathrm{M} \mathrm{NaCl}$ & [97] \\
\hline $\mathrm{TiO} 2$ nanocontainer & $\begin{array}{l}\text { 2-mercaptobenzimida- } \\
\text { zole (MBI) }\end{array}$ & $2 \mathrm{wt} \%$ & EIS and SKP & Q235 & $0.5 \mathrm{M} \mathrm{NaCl}$ & [98] \\
\hline Carbon nanosheets & $\begin{array}{l}\text { pyhtic acid and amino- } \\
\text { propyltriethoxysilane }\end{array}$ & $45 \mathrm{wt} \%$ & EIS & Q235 & $3.5 \mathrm{wt} \% \mathrm{NaCl}$ & [99] \\
\hline $\begin{array}{l}\text { Eudragit Polymeric } \\
\text { particles }\end{array}$ & 8-hydroxyquinoline & $10 \mathrm{wt} \%$ & $\begin{array}{l}\text { EIS, Localized electro- } \\
\text { chemical impedance } \\
\text { spectroscopy (LEIS) }\end{array}$ & AA2024 & $0.5 \mathrm{M} \mathrm{NaCl}$ & [96] \\
\hline $\mathrm{CeO} 2$ hollow spheres & Benzatriazole & $0.5 \mathrm{wt} \%$ & EIS and SKP & Q235 & $0.5 \mathrm{M} \mathrm{NaCl}$ & [100] \\
\hline Chitosan microspheres & Sodium phytate & $5 \mathrm{wt} \%$ & $\begin{array}{l}\text { EIS and sea water } \\
\text { immersion test }\end{array}$ & Copper & $3.5 \mathrm{wt} \% \mathrm{NaCl}$ & [101] \\
\hline $\mathrm{SiO}$ / Lacithin & Etidroic acid (HEDP) & $4 \mathrm{wt} \%$ & EIS, PDP, SST & Q235 & $3.5 \mathrm{wt} \% \mathrm{NaCl}$ & {$[102]$} \\
\hline
\end{tabular}

The major challenge that is faced in this field is the concern regarding the solubility of certain inhibitors in water along with the attainment of superhydrophobic character. Functionalisation of graphene with suitable material is a good way to achieve superhydrophobic characteristics or the
WEP coatings. The use of computational techniques such as density functional theory (DFT) in the selection of the filler and their interaction of the metal are not much explored in the field of generation of WEP coatings. The next challenge is the cost-effectiveness of the inhibitors when used on a 
Table 4 Advantages and disadvantages of various coating systems

\begin{tabular}{|c|c|c|}
\hline Material system & Advantages & Disadvantages \\
\hline Graphene incorporated WEP coatings & $\begin{array}{l}\text { Higher integrity and lower defects } \\
\text { High durability } \\
\text { Enhanced weathering resistance and mechani- } \\
\text { cal strength }\end{array}$ & $\begin{array}{l}\text { Reduction of material flow when the resin } \\
\text { is added to graphene, which may lead to } \\
\text { agglomeration. This may result in the forma- } \\
\text { tion of non uniform coating }\end{array}$ \\
\hline $\begin{array}{l}\text { Polymer incorporated water-based epoxy } \\
\text { coatings }\end{array}$ & $\begin{array}{l}\text { High conductivity of the coatings } \\
\text { Enhanced curing time and high electron den- } \\
\text { sity leads to greater adhesion for the coating }\end{array}$ & $\begin{array}{l}\text { The processibility of the non substituted } \\
\text { polymer material limits their practical } \\
\text { application } \\
\text { Less dispersion of polymers in WEP coating }\end{array}$ \\
\hline $\begin{array}{l}\text { Organic-inorganic hybrid particles incorpo- } \\
\text { rated into the water-based coating }\end{array}$ & $\begin{array}{l}\text { Good dispersion of particles } \\
\text { Less defects and Biocompatible }\end{array}$ & $\begin{array}{l}\text { Large scale up faces various challenges } \\
\text { Unfavourable reaction conditions such as high } \\
\text { temperature and pressure during the produc- } \\
\text { tion of the fillers }\end{array}$ \\
\hline Smart coating & $\begin{array}{l}\text { Double protection against corrosion } \\
\text { The nanocontainers prevent the negative effect } \\
\text { of corrosion inhibitor on the stability of the } \\
\text { coating }\end{array}$ & $\begin{array}{l}\text { Optimisation of the amount of nanocontainers } \\
\text { is difficult } \\
\text { In highly acidic conditions, the coatings are } \\
\text { found to be lesser effective }\end{array}$ \\
\hline
\end{tabular}

large industrial scale. The use of statistical techniques such as design of experiment can be employed during the scale up of the coating preparation which will in turn reduce the number of steps involved in the optimization of the concentration of the fillers. The use of water soluble biopolymers is not explored to the maximum, and their effect on corrosion resistance and curing time can be studied. Cost effective green MOFs can be developed, which can act as an excelled candidate as a filler. Thus, there is a great scope in the modification of water-based coating with higher characteristics and corrosion resistance.

Acknowledgements Ms. Jilna Jomy is grateful to Manipal Academy of Higher Education, Manipal, for awarding the Dr. TMA Pai scholarship.

Funding Open access funding provided by Manipal Academy of Higher Education, Manipal. The authors received no direct funding for this research article.

\section{Declarations}

Conflict of interest On behalf of all authors, the corresponding author states that there is no conflict of interest.

Open Access This article is licensed under a Creative Commons Attribution 4.0 International License, which permits use, sharing, adaptation, distribution and reproduction in any medium or format, as long as you give appropriate credit to the original author(s) and the source, provide a link to the Creative Commons licence, and indicate if changes were made. The images or other third party material in this article are included in the article's Creative Commons licence, unless indicated otherwise in a credit line to the material. If material is not included in the article's Creative Commons licence and your intended use is not permitted by statutory regulation or exceeds the permitted use, you will need to obtain permission directly from the copyright holder. To view a copy of this licence, visit http://creativecommons.org/licenses/by/4.0/.

\section{References}

1. Zaferani SH, Sharifi M, Zaarei D, Shishesaz MR (2013) Application of eco-friendly products as corrosion inhibitors for metals in acid pickling processes: A review. J Environ Chem Eng 1(4):652-657. https://doi.org/10.1016/j.jece.2013.09.019

2. Strehblow HH, Marcus P (2011) Fundamentals of corrosion. J (Am Water Works Assoc). https://doi.org/10.1002/j.1551-8833. 1941.tb19650.x

3. Wagner C (1952) Contribution to the theory of cathodic protection. J Electrochem Soc 99(1):1. https://doi.org/10.1149/1.27796 53

4. Silva RS, Aleman C, Ferreira CA, Armelin E, Ferreira JZ, Meneguzzi A (2015) Smart paint for anodic protection of steel. Prog Org Coat 78:116-123. https://doi.org/10.1016/j.porgcoat. 2014.10.002

5. Bahadori A (2014) Design considerations on cathodic protection for buried pipelines and marine structures. Cathodic Corrosion Protection Syst 1:91-131. https://doi.org/10.1016/ b978-0-12-800274-2.00003-x

6. Prabhu D, Rao P (2019) A comparative study on inhibitory actions of TCE, GIE, and CSE on the Corrosion of $6063 \mathrm{Al}$ Alloy in H3PO4 medium. J Bio- and Tribo-Corrosion. https:// doi.org/10.1007/s40735-019-0269-x

7. Hossain N, Chowdhury MA, Kchaou M (2021) An overview of green corrosion inhibitors for sustainable and environment friendly industrial development. J Adhesion Sci Technol 3(7):673-690. https://doi.org/10.1080/01694243.2020.18167 93

8. McKeen LW (2012) Introduction to permeation of plastics and elastomers. Permeab Prop Plast Elastom. https://doi.org/10.1016/ b978-1-4377-3469-0.10001-3

9. de Leon A, Advincula RC (2015) Conducting polymers with superhydrophobic effects as anticorrosion coating. Intell Coat Corrosion Control. https://doi.org/10.1016/B978-0-12-411467-8. 00011-8

10. de Wit JHW, van der Weijde DH, Ferrari G (2011) Organic coatings. Corrosion Mech Theory Pract. https://doi.org/10.1016/ b978-0-444-62722-3.00013-6

11. Dagdag O, El Gana L, Hamed O, Jodeh S, El Harfi A (2019) Anticorrosive formulation based of the epoxy resin-polyaminoamide containing zinc phosphate inhibitive pigment applied 
on sulfo-tartaric anodized AA 7075-T6 in NaCl medium. J BioTribo-Corrosion. https://doi.org/10.1007/s40735-019-0218-8

12. Cook MI, Walker FH, Dubowik DA (1999) Recent developments in two-pack water-based epoxy coatings. JOCCA 82(11):528535. https://doi.org/10.1007/bf02692657

13. Dagdag O et al (2020) Development and anti-corrosion performance of polymeric epoxy resin and their zinc phosphate composite on 15CDV6 steel in $3 \mathrm{wt} \% \mathrm{NaCl}$ : experimental and computational studies. J Bio-Tribo-Corrosion. https://doi.org/10. 1007/s40735-020-00407-1

14. Shi H et al (2021) Synthesis of carboxymethyl chitosan-functionalized graphene nanomaterial for anticorrosive reinforcement of waterborne epoxy coating. Carbohyd Polym 252:117249. https:// doi.org/10.1016/J.CARBPOL.2020.117249

15. Jlassi K et al (2018) Anti-corrosive and oil sensitive coatings based on epoxy/polyaniline/magnetite-clay composites through diazonium interfacial chemistry. Sci Rep 8(1):1-13. https://doi. org/10.1038/s41598-018-31508-0

16. Lee C, Wei X, Kysar JW, Hone J (2008) Measurement of the elastic properties and intrinsic strength of monolayer graphene. Science 321(5887):385-388. https://doi.org/10.1126/science. 1157996

17. Bolotin KI et al (2008) Ultrahigh electron mobility in suspended graphene. Solid State Commun 146(9-10):351-355. https://doi. org/10.1016/j.ssc.2008.02.024

18. Novoselov KS, Mishchenko A, Carvalho A, Neto AHC (2016) 2D materials and van der Waals heterostructures. Science. https://doi.org/10.1126/science.aac9439

19. Cui M, Ren S, Zhao H, Xue Q, Wang L (2018) Polydopamine coated graphene oxide for anticorrosive reinforcement of waterborne epoxy coating. Chem Eng J 335:255-266. https://doi.org/ 10.1016/j.cej.2017.10.172

20. Mas-Ballesté R, Gómez-Navarro C, Gómez-Herrero J, Zamora F (2011) 2D materials: to graphene and beyond. Nanoscale 3(1):20-30. https://doi.org/10.1039/c0nr00323a

21. Cui M et al (2018) Corrosion protection of water-borne epoxy coatings incorporated with graphene. Int J Electrochem Sci 13(12):12010-12023. https://doi.org/10.20964/2018.12.48

22. Zhou S, Wu Y, Zhao W, Yu J, Jiang F, Ma L (2018) Comparative corrosion resistance of graphene sheets with different structures in waterborne epoxy coatings. Colloids Surf A 556:273-283. https://doi.org/10.1016/j.colsurfa.2018.08.045

23. Song B et al (2015) Triethanolamine functionalized graphenebased composites for high performance supercapacitors. J Mater Chem A 3(43):21789-21796. https://doi.org/10.1039/c5ta0 $5674 \mathrm{~h}$

24. Qiu S, Li W, Zheng W, Zhao H, Wang L (2017) Synergistic effect of polypyrrole-intercalated graphene for enhanced corrosion protection of aqueous coating in $3.5 \% \mathrm{NaCl}$ solution Synergistic effect of polypyrrole-intercalated graphene for enhanced corrosion protection of aqueous coating in $3.5 \% \mathrm{~N}$. ACS Appl Mater Interfaces 9(39):34294-34304. https://doi.org/10.1021/acsami. $7 \mathrm{~b} 08325$

25. Monetta T, Acquesta A, Carangelo A, Bellucci F (2018) Considering the effect of graphene loading in water-based epoxy coatings. J Coat Technol Res 15(5):923-931. https://doi.org/10.1007/ s11998-018-0045-8

26. Su Y, Kravets VG, Wong SL, Waters J, Geim AK, Nair RR (2014) Impermeable barrier films and protective coatings based on reduced graphene oxide. Nat Commun 5:1-5. https://doi.org/ $10.1038 /$ ncomms 5843

27. Zhou X, Huang H, Zhu R, Sheng X, Xie D, Mei Y (2019) Facile modification of graphene oxide with Lysine for improving anticorrosion performances of water-borne epoxy coatings. Progress
Organic Coat 136(7):105200. https://doi.org/10.1016/j.porgcoat. 2019.06.046

28. Wang S et al (2018) Applied Surface Science Green synthesis of graphene with the assistance of modified lignin and its application in anticorrosive waterborne epoxy coatings". Appl Surf Sci 484(9):759-770. https://doi.org/10.1016/j.apsusc.2019.03.229

29. Zhou X et al (2020) Progress in Organic Coatings Green modification of graphene oxide with phytic acid and its application in anticorrosive water-borne epoxy coatings. Progress Organ Coat 143(2):105601. https://doi.org/10.1016/j.porgcoat.2020.105601

30. Wang N, Gao H, Zhang J, Kang P (2018) Effect of graphene oxide/ZSM-5 hybrid on corrosion resistance of waterborne epoxy coating. Coatings. https://doi.org/10.3390/coatings8050179

31. Li J et al (2020) Enhanced corrosion resistance and weathering resistance of waterborne epoxy coatings with polyetheraminefunctionalized graphene oxide. J Coat Technol Res 17(1):171180. https://doi.org/10.1007/s11998-019-00252-z

32. Huang $\mathrm{H}$ et al (2020) Modification of graphene oxide with acrylate phosphorus monomer via thiol-Michael addition click reaction to enhance the anti-corrosive performance of waterborne epoxy coatings. Progress Organ Coat 146(4):105724. https://doi. org/10.1016/j.porgcoat.2020.105724

33. Zhong F et al (2019) Graphene/V2O5@ polyaniline ternary composites enable waterborne epoxy coating with robust corrosion resistance. React Funct Polym 151(11):2020. https://doi.org/10. 1016/j.reactfunctpolym.2020.104567

34. Amani M, Shakeri A (2020) Synthesis and characterization of water-based epoxy-acrylate/graphene oxide decorated with $\mathrm{Fe} 3 \mathrm{O} 4$ nanoparticles coatings and its enhanced anticorrosion properties. Polym-Plast Technol Mater 59(17):1910-1931. https://doi.org/10.1080/25740881.2020.1773500

35. Xu HY, Li B, Han X, Wang Y, Zhang XR, Komarneni S (2019) Synergic enhancement of the anticorrosion properties of an epoxy coating by compositing with both graphene and halloysite nanotubes. J Appl Polym Sci 136(21):1-8. https://doi.org/10. 1002/app.47562

36. Ye Y, Chen H, Zou Y, Zhao H (2021) Study on self-healing and corrosion resistance behaviors of functionalized carbon dotintercalated graphene-based waterborne epoxy coating. J Mater Sci Technol 67:226-236. https://doi.org/10.1016/j.jmst.2020.06. 023

37. Zhu G, Hou J, Zhu H, Qiu R, Xu J (2013) Electrochemical synthesis of poly(3,4-ethylenedioxythiophene) on stainless steel and its corrosion inhibition performance. J Coat Technol Res 10(5):659-668. https://doi.org/10.1007/s11998-013-9482-6

38. Wen J, Tian Y, Mei Z, Wu W, Tian Y (2017) Synthesis of polypyrrole nanoparticles and their applications in electrically conductive adhesives for improving conductivity. RSC Adv 7(84):53219-53225. https://doi.org/10.1039/c7ra09725e

39. Dominis AJ, Spinks GM, Wallace GG (2003) Comparison of polyaniline primers prepared with different dopants for corrosion protection of steel. Prog Org Coat 48(1):43-49. https://doi.org/ 10.1016/S0300-9440(03)00111-5

40. Barroso MM (2013) Formulation of anticorrosive paints employing conducting polymers

41. Zaarei D, Sarabi AA, Sharif F, Kassiriha SM (2008) Structure, properties and corrosion resistivity of polymeric nanocomposite coatings based on layered silicates. J Coat Technol Res 5(2):241249. https://doi.org/10.1007/s11998-007-9065-5

42. Minto CDG, Vaughan AS (1996) Partial phase mixing in solution-processed polyaniline-poly(methyl methacrylate) blends. Synth Met 81(1):81-86. https://doi.org/10.1016/0379-6779(96) 80233-5 
43. Chen Y, Wang XH, Li J, Lu JL, Wang FS (2007) Long-term anticorrosion behaviour of polyaniline on mild steel. Corros Sci 49(7):3052-3063. https://doi.org/10.1016/j.corsci.2006.11.007

44. Akbarinezhad E, Ebrahimi M, Faridi HR (2009) Corrosion inhibition of steel in sodium chloride solution by undoped polyaniline epoxy blend coating. Prog Org Coat 64(4):361-364. https:// doi.org/10.1016/j.porgcoat.2008.07.018

45. Bagherzadeh MR, Ghasemi M, Mahdavi F, Shariatpanahi H (2011) Investigation on anticorrosion performance of nano and micro polyaniline in new water-based epoxy coating. Prog Org Coat 72(3):348-352. https://doi.org/10.1016/j.porgcoat.2011.05. 007

46. Bagherzadeh MR, Mahdavi F, Ghasemi M, Shariatpanahi H, Faridi HR (2010) Using nanoemeraldine salt-polyaniline for preparation of a new anticorrosive water-based epoxy coating. Prog Org Coat 68(4):319-322. https://doi.org/10.1016/j.porgc oat.2010.03.005

47. Bhadra S, Khastgir D, Singha NK, Lee JH (2009) Progress in preparation, processing and applications of polyaniline. Progress Polym Sci (Oxford) 34(8):783-810. https://doi.org/10.1016/j. progpolymsci.2009.04.003

48. Jang J, Bae J, Lee K (2005) Synthesis and characterization of polyaniline nanorods as curing agent and nanofiller for epoxy matrix composite. Polymer 46(11):3677-3684. https://doi.org/ 10.1016/j.polymer.2005.03.030

49. Chen J, Chao D, Lu X, Zhang W (2007) Novel interfacial polymerization for radially oriented polyaniline nanofibers. Mater Lett 61(6):1419-1423. https://doi.org/10.1016/j.matlet.2006.07.043

50. Qiu S, Chen C, Cui M, Li W, Zhao H, Wang L (2017) Applied Surface science corrosion protection performance of waterborne epoxy coatings containing self-doped polyaniline nanofiber. Appl Surf Sci 407:213-222. https://doi.org/10.1016/j.apsusc.2017.02. 142

51. Gu L, Ding JH, Liu S, Bin Yu H (2016) Incorporation of reactive corrosion inhibitor in waterborne acrylic polyurethane coatings and evaluation of its corrosion performance. Chin J Chem Phys 29(2):271-278. https://doi.org/10.1063/1674-0068/29/cjcp1 507156

52. Simões AM, Torres J, Picciochi R, Fernandes JCS (2009) Corrosion inhibition at galvanized steel cut edges by phosphate pigments. Electrochim Acta 54(15):3857-3865. https://doi.org/10. 1016/j.electacta.2009.01.065

53. Chen F, Liu P (2011) Conducting polyaniline nanoparticles and their dispersion for waterborne corrosion protection coatings. ACS Appl Mater Interfaces 3(7):2694-2702. https://doi.org/10. 1021/am200488m

54. Kalendova A, Vesely D, Stejskal J, Nemec P (2009) Corrosion inhibition efficiency of organic coatings with content of polyaniline phosphate. Mater Res Innov 13(3):295-297. https://doi.org/ 10.1179/143307509X440578

55. Gu L et al (2016) Facile preparation of polyaniline nanoparticles and their dispersion for waterborne anticorrosion coatings. Int $\mathrm{J}$ Electrochem Sci 11(2):1621-1631

56. Yang M, Wu J, Fang D, Li B, Yang Y (2018) Corrosion protection of waterborne epoxy coatings containing mussel-inspired adhesive polymers based on polyaspartamide derivatives on carbon steel. J Mater Sci Technol 34(12):2464-2471. https://doi.org/ 10.1016/j.jmst.2018.05.009

57. Wang N, Fu W, Zhang J, Li X, Fang Q (2015) Corrosion performance of waterborne epoxy coatings containing polyethylenimine treated mesoporous-TiO2 nanoparticles on mild steel. Prog Org Coat 89:114-122. https://doi.org/10.1016/j.porgcoat.2015. 07.009

58. Ai L, Liu Y, Zhang XY, Ouyang XH, Ge ZY (2014) A facile and template-free method for preparation of polythiophene microspheres and their dispersion for waterborne corrosion protection coatings. Synth Met 191:41-46. https://doi.org/10.1016/j. synthmet.2014.02.004

59. Wang N, Wu YH, Cheng KQ, Zhang J (2014) Investigation on anticorrosion performance of polyaniline-mesoporous MCM41 composites in new water-based epoxy coating. Mater Corros 65(10):968-976. https://doi.org/10.1002/maco.201307458

60. Liu X, Hou P, Zhao X, Ma X, Hou B (2019) The polyanilinemodified $\mathrm{TiO} 2$ composites in water-based epoxy coating for corrosion protection of Q235 steel. J Coat Technol Res 16(1):71-80. https://doi.org/10.1007/s11998-018-0101-4

61. Li YF, Gao XH, Zhu HL, Yang L (2009) Water-based polyaniline/montmorillonite/epoxy composite coatings for the corrosion protection of mild steel. Adv Mater Res 79-82:1067-1070. https://doi.org/10.4028/www.scientific.net/AMR.79-82.1067

62. Zhang $\mathrm{C}$ et al (2020) Designing a high-performance waterborne epoxy coating with passive/active dual self-healing properties by synergistic effect of V2O5@polyaniline-tannic acid inhibitors. Prog Org Coat 151(10):2021. https://doi.org/10.1016/j.porgcoat. 2020.106036

63. Bagherzadeh MR, Daneshvar A, Shariatpanahi H (2012) Novel water-based nanosiloxane epoxy coating for corrosion protection of carbon steel. Surf Coat Technol 206(8-9):2057-2063. https:// doi.org/10.1016/j.surfcoat.2011.05.036

64. Zhang D, Wang L, Qian H, Li X (2016) Superhydrophobic surfaces for corrosion protection: a review of recent progresses and future directions. J Coat Technol Res 13(1):11-29. https://doi. org/10.1007/s11998-015-9744-6

65. van Ooij WJ et al (2005) Corrosion protection properties of organofunctional silanes: an overview. Tsinghua Sci Technol 10(6):639-664. https://doi.org/10.1016/S1007-0214(05)70134-6

66. Qian M, Mcintosh Soutar A, Tan XH, Zeng XT, Wijesinghe SL (2009) Two-part epoxy-siloxane hybrid corrosion protection coatings for carbon steel. Thin Solid Films 517(17):5237-5242. https://doi.org/10.1016/j.tsf.2009.03.114

67. Chang CC, Oyang TY, Chen YC, Hwang FH, Cheng LP (2014) Preparation of hydrophobic nanosilica-filled polyacrylate hard coatings on plastic substrates. J Coat Technol Res 11(3):381386. https://doi.org/10.1007/s11998-013-9540-0

68. Ou J et al (2010) Construction and study on corrosion protective property of polydopamine-based 3-layer organic coatings on aluminum substrate. Prog Org Coat 68(3):244-247. https://doi. org/10.1016/j.porgcoat.2010.01.004

69. Jahan M, Bao Q, Yang JX, Loh KP (2010) Structure-directing role of graphene in the synthesis of metal-organic framework nanowire. J Am Chem Soc 132(41):14487-14495. https://doi. org/10.1021/ja105089w

70. Choi KM, Park JH, Kang JK (2015) Nanocrystalline MOFs embedded in the crystals of other MOFs and their multifunctional performance for molecular encapsulation and energycarrier storage. Chem Mater 27(14):5088-5093. https://doi.org/ 10.1021/acs.chemmater.5b01786

71. Wang TC et al (2015) Ultrahigh surface area zirconium MOFs and insights into the applicability of the BET Theory. J Am Chem Soc 137(10):3585-3591. https://doi.org/10.1021/ja512 973b

72. Wang N, Zhang Y, Chen J, Zhang J, Fang Q (2017) Dopamine modified metal-organic frameworks on anti-corrosion properties of waterborne epoxy coatings. Prog Org Coat 109(5):126-134. https://doi.org/10.1016/j.porgcoat.2017.04.024

73. Shchukin DG, Zheludkevich M, Yasakau K, Lamaka S, Ferreira MGS, Möhwald H (2006) Layer-by-layer assembled nanocontainers for self-healing corrosion protection. Adv Mater 18(13):1672-1678. https://doi.org/10.1002/adma.200502053 
74. Wolfram LF, Montemor FF (2011) European Federation of Corrosion., and M. Institute of Materials, Self-healing properties of new surface treatments, 58th ed., no. 58. European Federation of Corrosion Publications

75. Murphy EB, Wudl F (2010) The world of smart healable materials. Progress Polym Sci (Oxford) 35(1-2):223-251. https://doi. org/10.1016/j.progpolymsci.2009.10.006

76. Montemor MF, Ferreira MGS (2007) Electrochemical study of modified bis-[triethoxysilylpropyl] tetrasulfide silane films applied on the AZ31 Mg alloy. Electrochim Acta 52(27):74867495. https://doi.org/10.1016/j.electacta.2006.12.086

77. Garcia-Heras M, Jimenez-Morales A, Casal B, Galvan JC, Radzki S, Villegas MA (2004) Preparation and electrochemical study of cerium-silica sol-gel thin films. J Alloys Compds 380(1-2):219-224. https://doi.org/10.1016/j.jallcom.2004.03. 047

78. Lamaka SV, Shchukin DG, Andreeva DV, Zheludkevich ML, Möhwald H, Ferreira MGS (2008) Sol-gel/polyelectrolyte active corrosion protection system. Adv Func Mater 18(20):3137-3147. https://doi.org/10.1002/adfm.200800630

79. Tedim J et al (2010) Enhancement of active corrosion protection via combination of inhibitor-loaded nanocontainers. ACS Appl Mater Interfaces 2(5):1528-1535. https://doi.org/10.1021/am100 $174 \mathrm{t}$

80. Zheludkevich ML et al (2010) Active protection coatings with layered double hydroxide nanocontainers of corrosion inhibitor. Corros Sci 52(2):602-611. https://doi.org/10.1016/j.corsci.2009. 10.020

81. Zheludkevich ML, Shchukin DG, Yasakau KA, Möhwald H, Ferreira MGS (2007) Anticorrosion coatings with self-healing effect based on nanocontainers impregnated with corrosion inhibitor. Chem Mater 19(3):402-411. https://doi.org/10.1021/cm062066k

82. Skorb EV, Skirtach AG, Sviridov DV, Shchukin DG, Möhwald H (2009) Laser-controllable coatings for corrosion protection. ACS Nano 3(7):1753-1760. https://doi.org/10.1021/nn900347x

83. Kendig M, Kinlen P (2007) Demonstration of galvanically stimulated release of a corrosion inhibitor. J Electrochem Soc 154(4):C195. https://doi.org/10.1149/1.2436628

84. Snihirova D et al (2010) Hydroxyapatite microparticles as feedback-active reservoirs of corrosion inhibitors. ACS Appl Mater Interfaces 2(11):3011-3022. https://doi.org/10.1021/am1005942

85. Shchukin DG, Möhwald H (2007) Surface-engineered nanocontainers for entrapment of corrosion inhibitors. Adv Func Mater 17(9):1451-1458. https://doi.org/10.1002/adfm.200601226

86. Cong Y, Chen K, Zhou S, Wu L (2015) Synthesis of pH and UV dual-responsive microcapsules with high loading capacity and their application in self-healing hydrophobic coatings. J Mater Chem A 3(37):19093-19099. https://doi.org/10.1039/c5ta04986e

87. Chen S, Li X, Li Y, Sun J, Al CET (2015) Intumescent flameretardant and coatings on cotton fabric. ACS Nano 4:4070-4076

88. Chen K, Zhou S, Wu L (2014) Facile fabrication of self-repairing superhydrophobic coatings. Chem Commun 50(80):1189111894. https://doi.org/10.1039/c3cc49251f

89. Xue CH, Zhang ZD, Zhang J, Jia ST (2014) Lasting and selfhealing superhydrophobic surfaces by coating of polystyrene/ $\mathrm{SiO} 2$ nanoparticles and polydimethylsiloxane. J Mater Chem A 2(36):15001-15007. https://doi.org/10.1039/c4ta02396j

90. Wang H, Xue Y, Ding J, Feng L, Wang X, Lin T (2011) Durable, self-healing superhydrophobic and superoleophobic surfaces from fluorinated-decyl polyhedral oligomeric silsesquioxane and hydrolyzed fluorinated alkyl silane. Angew Chem 123(48):11635-11638. https://doi.org/10.1002/ange.201105069
91. Manna U, Lynn DM (2013) Restoration of superhydrophobicity in crushed polymer films by treatment with water: self-healing and recovery of damaged topographic features aided by an unlikely source. Adv Mater 25(36):5104-5108. https://doi.org/ 10.1002/adma.201302217

92. Liu Y, Pei X, Liu Z, Yu B, Yan P, Zhou F (2015) Accelerating the healing of superhydrophobicity through photothermogenesis. J Mater Chem A 3(33):17074-17079. https://doi.org/10.1039/ c5ta04252f

93. Kinlen PJ, Menon V, Ding Y (1999) A mechanistic investigation of polyaniline corrosion protection using the scanning reference electrode technique. J Electrochem Soc 146(10):3690-3695. https://doi.org/10.1149/1.1392535

94. Snihirova D, Lamaka SV, Montemor MF (2012) Smart protective ability of water based epoxy coatings loaded with $\mathrm{CaCO}$ 3 microbeads impregnated with corrosion inhibitors applied on AA2024 substrates. Electrochim Acta 83:439-447. https://doi. org/10.1016/j.electacta.2012.07.102

95. Kopeć M et al (2015) Self-healing epoxy coatings loaded with inhibitor-containing polyelectrolyte nanocapsules. Prog Org Coat 84:97-106. https://doi.org/10.1016/j.porgcoat.2015.02.011

96. Snihirova D, Lamaka SV, Cardoso MM, Condeço JAD, Ferreira HECS, De Fatima Montemor M (2014) PH-sensitive polymeric particles with increased inhibitor-loading capacity as smart additives for corrosion protective coatings for AA2024. Electrochim Acta 145:123-131. https://doi.org/10.1016/j.electacta.2014.09. 009

97. Liu X, Zheng M, Hongtao T, Kaiwei L, Baorong H (2020) Water-based epoxy coatings with $\mathrm{pH}$-sensitive $\mathrm{TiO} 2$ containers for active corrosion protection of carbon steel. Corros Eng, Sci Technol 55(8):645-654. https://doi.org/10.1080/1478422X.2020. 1772527

98. Liu X, Gu C, Ma Z, Ma X, Hou B (2018) pH-responsive containers based on modified hollow TiO 2 for active and passive protection of carbon steel. J Electrochem Soc 165(3):C145-C154. https://doi.org/10.1149/2.0011803jes

99. Gao X, Yan R, Lv Y, Ma H, Ma H (2020) In situ pretreatment and self-healing smart anti-corrosion coating prepared through eco-friendly water-base epoxy resin combined with non-toxic chelating agents decorated biomass porous carbon. J Clean Prod 266:121920. https://doi.org/10.1016/j.jclepro.2020.121920

100. Liu X, Gu C, Wen Z, Hou B (2017) Improvement of active corrosion protection of carbon steel by water-based epoxy coating with smart $\mathrm{CeO} 2$ nanocontainers. Progress Organ Coats 115(10):195204. https://doi.org/10.1016/j.porgcoat.2017.10.015

101. Liu X et al (2018) Synthesis and characterization of pH-responsive mesoporous chitosan microspheres loaded with sodium phytate for smart water-based coatings. Mater Corros 69(6):736748. https://doi.org/10.1002/maco.201709840

102. Wang $C$ et al (2021) Novel environmentally friendly waterborne epoxy coating with long-term antiscaling and anticorrosion properties. Langmuir 37(31):9439-9450. https://doi.org/10.1021/acs. langmuir.1c01124

Publisher's Note Springer Nature remains neutral with regard to jurisdictional claims in published maps and institutional affiliations. 